\title{
Karel kosik: Diálogos com a Filosofia Kantiana
}

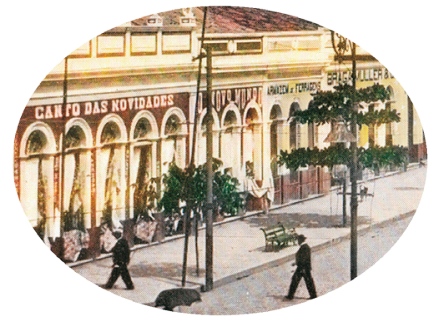

Victor Leandro da Silva*

\section{Resumo}

O caminho traçado pela epistemologia de Karel Kosik está profundamente relacionado aos princípios estabelecidos por Immanuel Kant. Assim, para compreender o pensamento do filósofo tcheco, é fundamental que se determinem os elementos que permitem ligá-lo à teoria do conhecimento kantiana, bem como os termos que promovem a dissociação entre eles e possibilitam a aproximação entre Kosik de Karl Marx, cuja obra é o cerne de suas reflexões.

Palavras-chave: Pseudoconcreticidade; epistemologia; representação; coisaem-si.

\begin{abstract}
The path created by Karel Kosik's epistemology is deeply related to the principles set by Immanuel Kant. Therefore, it's fundamental to the understanding of the ideas of the Czech philosopher, the determination of the elements that may connect them to Kant's theory of knowledge as to their dissociative terms, that bring Karl Kosik close to Karl Marx, whose work is the core of Kosik's reflections.
\end{abstract}

Keywords: Pseudoconcreticity; epistemology; representation; thing in itself.

\footnotetext{
* Licenciado em Filosofia pela Ufam. Mestrando no Programa de Pós-Graduação em Sociedade e Cultura na Amazônia. E-mail: viktorleandro@hotmail.com
} 


\section{Introdução}

As discussões acerca da origem do conhecimento, desde a antiguidade e principalmente na era moderna, sempre giraram em torno de duas teses principais. De um lado, havia os que consideravam que os sentidos forneciam dados enganosos a respeito da realidade, e que somente a razão seria capaz de produzir conceitos verdadeiros acerca dos objetos presentes no mundo. Esta é a visão do racionalismo, que encontrou em Descartes (MOROZ, RUBANO, 1999) o seu grande defensor dentro do período moderno.

De outro lado, estavam aqueles que consideravam que a razão somente pensava os dados, mas que era a experiência que seria capaz de obtê-los em sua verdadeira essência, sendo que a verdade de um objeto seria a sua completa percepção daquilo que a sensibilidade obtinha. Essa era a tese empirista. Tal perspectiva, amparada na ascensão do conhecimento científico, tornou-se cada vez mais aceita no meio filosófico, principalmente por estar de acordo com os novos caminhos que despontavam no cenário político-social da Europa moderna. O progresso dessas teorias foi fundamental para a consolidação da ciência.

Como tentativa de conciliar as duas hipóteses, e de pôr fim a uma discussão secular, Immanuel Kant (1985) procurou empreender uma obra que desse conta de conferir a sua real função tanto à razão quanto à experiência. Tal obra é a Crítica da razão pura, que constituiu-se numa intensa investigação sobre os limites e possibilidades do conhecer humano. Após esta obra, o debate epistemológico, inconcluso até aquele momento, parecia ter chegado ao seu termo.

A partir daí, a discussão em torno do conhecimento se deu por diversas perspectivas, estando algumas bem próximas do que pretendia Kant, outras procurando distanciar-se dele ao máximo, na tentativa de enveredar pelos caminhos que estivessem mais ligados aos princípios das ciências particulares, que se encontravam em processo de pleno desenvolvimento.

Um deles éKarl Marx (2002) que, partindo de uma concepção materialista, propôs que a realidade devia ser observada através de suas transformações históricas, e que os elementos dados no mundo não possuem uma existência fora daquilo que nossos sentidos nos fornecem, ou uma essência que esteja além da percepção humana, como queriam os racionalistas ou até mesmo Kant. As 
coisas são exatamente como se apresentam ao homem, cabendo a ele apenas analisá-las corretamente, a fim de determinar-lhes a essência. Tal concepção foi bastante significativa para a fundamentação das ciências humanas.

Com isso, abriu-se um grande leque de teorias epistemológicas que, na contemporaneidade, permitiram a elaboração de obras que deram contribuições tanto ao campo da teoria do conhecimento, quanto ao avanço do saber científico, usando ora uma base kantiana, ora valendo-se de teorias mais próximas do pragmatismo e do materialismo marxiano.

Nesse contexto, encontra-se o pensamento de Karel Kosik (2002) e seu projeto de reelaboração do pensamento de Marx. Porém, mais do que repensar o marxianismo, o que também chama a atenção em Kosik é a sua tentativa de fundamentar uma teoria epistemológica nos pressupostos kantianos e, ao mesmo tempo, situá-la em consonância com os preceitos da filosofia de Marx.

\section{O mundo da pseudoconcreticidade e suas relações com a filosofia de Kant}

Dentro da teoria epistemológica empreendida pelo filósofo tcheco Karel Kosik, é possível encontrar uma significativa relação com a estética transcendental kantiana, relação esta que, longe de configurar-se apenas como um ponto de partida para as análises epistemológicas de Kosik, constitui-se num diálogo intenso e criador, em que é possível perceber diversas diferenças e aproximações entre os dois filósofos.

Em sua obra Dialética do Concreto (2002), Kosik, mesmo usando uma matriz teórica marxiana, ao abordar o problema do conhecimento, retoma a questão do fenômeno e da coisa em si discutida em Kant, porém agora sob a perspectiva de uma pseudoconcreticidade e de sua destituição. Sua ideia é mostrar que a transposição do mundo fenomênico para chegar aos conceitos se dá não somente de acordo com os limites cognitivos do sujeito do conhecimento, mas sobretudo em razão de uma atitude epistemológica:

A dialética trata da "coisa em si", mas a "coisa em si" não se manifesta imediatamente ao homem. Para chegar à sua compreensão, é necessário fazer não só um certo esforço, mas também um "detour". Por este motivo o pensamento dialético distingue entre representação e conceito da coisa, 
com isso não pretendendo apenas distinguir duas formas e dois graus de conhecimento da realidade, mas especialmente e sobretudo duas qualidades da práxis humana (KOSIK, 2002, p. 13)

Aqui, temos um dado fundamentalmente importante. A coisa em si é possível ao homem, sendo esta um objeto da dialética. Porém, o indivíduo não atinge a coisa em si senão por um desvio que está intimamente ligado a uma nova forma de agir perante a humanidade. Para Kosik, o ser humano não se apresenta ao mundo como puro sujeito do conhecimento, mas como alguém que age e retira de sua práxis diária um intuição das coisas. Porém, esta intuição está ligada exclusivamente ao universo fenomênico, o das coisas aparentes, de modo que por meio dela é possível obter uma representação do mundo, sem no entanto, desvendar sua estrutura, sua essência. Ao pensamento que se mostra preso a essas formas fenomênicas, Kosik irá denominar pensamento comum, o qual, devido a sua superficialidade, não pode criticamente vislumbrar a categoria de conceito.

O problema irá surgir quando essas representações ou senso comum assumem uma autonomia em relação a sua essência, em razão da práxis humana que concede à representação a aparência de realidade total e concreta. Os homens, habituados que estão a utilizar os elementos da realidade fenomênica, tomam-na como absoluta, ficando presos a esta atmosfera. Assim, eles jamais podem chegar a conhecer algo verdadeiramente, pois a sua representação cotidiana tornou-se de tal modo independente e natural que ganhou estatuto de realidade una e incontornável, à qual o ser humano está imanentemente restrito. A este estado de autonomia ontológica do mundo fenomênico, Karel Kosic dará o nome de pseudoconcreticidade.

Como exemplo desse mundo de representações, Kosik nos apresentará o dinheiro. Ele é manejado livremente e com propriedade por diversos indivíduos. No entanto, nenhum deles está interessado no que o dinheiro é realmente, ou sobre qual será a sua essência. Eles preferem permanecer com a noção que lhes é dada pelo senso comum, tornando absoluta a verdade que esse senso lhes concede. Eis o mundo pseudoconcreto, do qual fazem parte os fenômenos externos, o tráfico e a manipulação, as representações comuns e os objetos fixados. 
O mundo dos fenômenos externos corresponde aos processos que se desenvolvem na superfície da essência. Já o mundo do tráfico e da manipulação detém as práticas fetichizadas, ou seja, as representações tomadas à margem da crítica. O mundo das representações comuns, como consequência da prática fetichizada, irá criar ideias que se desenvolverão e irão dar origem aos diversos juízos, construindo assim as formas ideológicas, enquanto que os objetos fixados são tomados como naturais e integrantes da realidade, e não como resultado da atividade social humana.

O que advém desses quatromundosconstituintes dapseudoconcreticidade é um universo onde a representação não pode mais ser tomada em seu sentido real, mas como um elemento natural que se encontra num estágio anterior ao da atividade social humana. Os objetos, em vista disso, perdem a necessidade de serem pensados, e, quando o são, a única orientação que se obtém deles é quanto ao seu papel dentro das formas de representação, nunca ultrapassando-o para alcançar sua essência. Assim, o verdadeiro concreto se perde na representação desses mundos ilusórios.

Logo, é a este mundo pseudoconcreto que se confere um caráter de absoluta realidade, no qual a essência é indicada, em razão dessa indicação, também oculta. Desse modo, o fenômeno, munido de estrutura e ordenação próprias, assume caráter amplamente autônomo, podendo ser abordado e disposto em seus elementos constituintes, sem no entanto, relacionar-se claramente com a essência das coisas.

Contudo, para Kosik, o mundo fenomênico está longe de dissociar-se da essência, de constituir-se como realidade apartada da coisa em si. Ambos se interligam e relacionam, construindo uma unidade que se manifesta num constante jogo de claro-escuro entre o fenômeno e a essência.

Se a essência não se manifestasse absolutamente no mundo fenomênico, o mundo da realidade se distinguiria radical e essencialmente do mundo do fenômeno, em tal caso o mundo da realidade seria para o homem "o outro mundo" (platonismo, cristianismo) e o único mundo ao alcance do homem seria o mundo dos fenômenos (KOSIK, 2002, p. 15). 
A menção feita ao platonismo e ao cristianismo não é gratuita. Em verdade, tanto o pensamento platônico quanto o cristão representam a antítese daquilo que Kosik toma como fundamento para suas teorias.

A hipótese platônica de um mundo inteligível acima da sensibilidade e de que o mundo em que estamos representa apenas uma cópia malfeita deste primeiro é inaceitável para Kosik. Pensar que o mundo irá se dividir em dois e que aquilo que conhecemos através de nossos sentidos é algo totalmente ilusório, e que somente por meio do intelecto poderemos chegar a um conhecimento verdadeiro das coisas, sendo a verdade apenas um exercício de rememoração, é, para Kosik, algo totalmente inadmissível. A divisão platônica dos dois mundos nada mais é que um obstáculo à elaboração de um conhecimento real dos objetos, pois, se a verdade reside num outro plano que não este, ela é de natureza totalmente distinta desta que conhecemos, constituindose num mundo totalmente independente e autônomo. Se, por outro lado, considerarmos que esta autonomia chega a um caráter absoluto, é possível tomar este mundo sensível platônico, esta cópia de um outro mundo ideal e perfeito, como tendo ampla relação com o mundo da pseudoconcreticidade descrito por Kosik. Porém, tentar ligar uma teoria que se fundamenta na existência de dois mundo a uma outra que afirma que toda a verdade pode ser obtida por meio de uma investigação rigorosa dos dados que estão à volta do homem é algo que não encontra amparo para sua realização. O que Kosik propõe com sua ideia de pseudoconcreticidade é que a representação, tomada em sua forma mais potencializada, pode ganhar uma autonomia própria e uma independência, a qual pode conduzir o homem a considerá-la como realidade única e possível. Porém, de nenhuma forma é possível tomar este mundo da representação como gerado de modo independente da essência, pois, se assim o fosse, ele seria totalmente diferenciado dela, sendo impossível a sua constatação, o que, para Kosik, está longe de ser verdadeiro. A representação, mais do que ligar-se à essência, a sugere e aponta. Ambas estão relacionadas, fazendo parte de um mesmo conjunto. O mundo pseudoconcreto não é uma deformação de um outro essencial, onde tudo se apresenta no pleno exercício de sua verdade. Ele é uma forma de representação e, como tal, apresenta elementos autônomos e, assim também continua vinculado à essência da qual se origina, integrando com isso um mesmo plano de realidade. 
Ao cristianismo, a crítica feita por Kosik relaciona-se com sua rejeição a uma hipótese metafísica. Se existe um ser divino do qual todas as coisas se originam, a essência das coisas deve se encontrar nele e não mais no mundo. E como este ser divino está além da apreensão humana, o conhecimento da coisa em si também é irrealizável. Portanto, a concepção cristã do conhecimento não pode ser aceita.

As duas visões mencionadas, a cristã e a platônica, são combatidas por Kosik por ferir um dos princípios básicos da dialética do concreto, o de que o conhecimento da realidade não está fora deste mundo, e de que as coisas tais como aparecem e tais como são não podem estar totalmente separadas entre si, do contrário não haveria correspondência entre elas.

Assim, o mundo fenomênico e a essência estão intimamente relacionados, pertencendo a uma mesma unidade, sendo que as diversas transformações ocorridas no mundo dos fenômenos são geradas devido a sua relação com a essência. Mas, para o indivíduo, a coisa em si não se revela diretamente, e pode ser alcançada somente se pudermos conhecer e descrever o fenômeno. O fenômeno é, portanto, a porta de entrada para a essência, a qual só pode ser desvelada mediante a compreensão do mundo fenomênico, que é onde a essência se manifesta. Logo, a realidade será entendida somente se fizermos este caminho que vai do fenômeno à essência, sem jamais considerarmos ambos como termos isolados entre si.

E, como a coisa em si não se dá claramente ao indivíduo; é preciso que se desenvolvam métodos para que se chegue até ela. Para tanto, é que foram criadas as ciências e a Filosofia. Isso confirma a autonomia do fenômeno e da coisa em si, pois, se os dois fossem idênticos, seria desnecessário procurar por um ou por outro, e as pesquisas filosófica e científica não teriam sentido.

Nesse ponto, é possível dizer que a ciência e a Filosofia terão uma importância pragmática, conforme seu grau de contribuição para se chegar à essência das coisas. No caso do conhecimento científico, analisar essa importância é uma tarefa relativamente mais simples, em função do caráter prático e material das investigações científicas. Porém, com relação à Filosofia, determinar sua real contribuição para a produção de um conhecimento válido de acordo com os critérios estabelecidos por Kosik requer uma leitura mais detalhada, em razão das próprias características da pesquisa filosófica. 
A Filosofia, enquanto investigação fundamentalmente teórica, traz problemáticas que muitas vezes são estritamente racionais, sem qualquer relação com os objetos dados no mundo, sendo a metafísica, ou a ontologia, o exemplo mais bem elaborado disso, já que esta se caracteriza como um exercício puro da razão. Portanto, a reflexão filosófica está muitas vezes distante de um projeto de compreensão dos objetos sensíveis e da matéria.

Consequentemente, segundo a análise de Kosik, não se pode considerar todo o conhecimento da Filosofia como tendo valor para a dialética do concreto, pois, se seu objetivo é propiciar meios para que se atinja a essência das coisas, essência esta que está constituída na realidade e que se manifesta em relação com seus modos representativos, um pensamento que se mostra apenas teórico e não leva em conta os dados da concreticidade não pode ser validado, posto que este não atende aos reais objetivos pelos quais a Filosofia e as ciências foram criadas, que são os de tornar claro o movimento que conduz da representação à essência e também compreender o real em sua totalidade, o que, sem uma reflexão aguda e radical que aponte para esse fim, é inviável. Logo, o conhecimento que não possui ligação com a atividade humana e o mundo material está automaticamente destituído de significado. Assim, para Kosik, o campo de atividade da reflexão filosófica deve ser também o das ações humanas, e, quanto mais a Filosofia aproximar-se desse objetivo, mais ela se tornará necessária para a obtenção da verdade.

Entretanto, Kosik não deixa de recorrer a conceitos puramente intelectuais para construir seu pensamento. Em verdade, a dialética do concreto, como tentativa de agregar todo um conjunto de noções interpretativas da realidade, irá partir da pergunta inicial de como esta realidade pode ser entendida, e, para que tal se realize, é preciso se perguntar antes sobre aquilo que é dado ao ser humano conhecer e como ocorre o processo de produção do conhecimento.

Daí surge a aproximação entre Kosik e Kant. Os dois autores, preocupados com o problema da essência e do fenômeno, acabaram por trilhar um caminho que foi conduzido pelas mesmas perguntas, porém obtendo resultados diversos. Olhando mais atentamente, percebe-se que o arcabouço montado por eles guarda semelhanças bastante significativas.

Não se trata aqui de dissociar o pensamento Kosikiano da filosofia de Marx. A dialética do concreto é toda ela erigida com base no pensamento marxiano, e tem verdadeiramente o propósito de redimensioná-lo, residindo 
nisso o objetivo precípuo da obra. Logo, desvincular a obra desse paradigma é retirá-la de seu contexto.

O que se percebe é que, à parte as concepções filosóficas de Marx, é possível dizer que Kosik travou um forte diálogo com a filosofia kantiana, e que este diálogo mostrou-se bastante promissor, o que conduz obrigatoriamente ao estudo dessas relações de pensamento, a fim de determinar as proposições que delas podem ser retiradas.

Com isso, a pergunta que surge é como o pensamento kantiano interferiu na epistemologia elaborada por Kosik e de que forma as duas teorias se aproximam, e em que momento ocorre o distanciamento entre elas para que tenha lugar a filosofia marxiana. E, para que isso possa ser feito, é necessário que se faça um alinhamento das três teorias a fim de que se encontrem os seus aspectos convergentes e destoantes, e que se possa com isso também perceber os diversos componentes que Kosik acrescenta e que permitem formular novas enunciações que aparecem como o resultado do encontro e do entrelaçamento dessas três filosofias.

Na leitura da Dialética do Concreto, é possível observar que não há apenas uma proximidade entre o pensamento de Kosik e a filosofia Kantiana, mas também uma autêntica releitura da estética transcendental exposta na Crítica da raz̃ão pura (1985). Nesta obra, Kant irá discutir sobre de que maneira é possível ao homem conhecer, e quais são os limites deste conhecimento. Para tanto, Kant tratou de solucionar o impasse existente entre empirismo e racionalismo, asseverando que todo conhecimento se inicia com a experiência, mas nem sempre deriva dela. Ou seja, os dados obtidos através da observação da realidade são os mesmos que vão fundamentar as formas de compreender o mundo, o que não impede que possamos produzir conhecimentos puramente racionais, sendo o grande exemplo disso a matemática, que consiste num exercício puramente lógico, porém capaz de dar conta de resolver problemas da realidade.

Kant dividiu o conhecimento em dois juízos, o sintético e o analítico, onde coube ao primeiro ampliar conhecimento, enquanto que o segundo apenas o clarifica. Os juízos sintéticos são dados a posteriori, pois se constroem depois da experiência. Já os juízos analíticos são feitos a priori, pois estão num ponto anterior a ela. Porém, Kant irá apontar para uma terceira alternativa, que são os juízos sintéticos a priori, em que o conhecimento é ampliado, mas 
de forma inteiramente racional, quer dizer, num ponto que se encontra antes da experimentação.

Quanto à apreensão dos objetos pelo homem, Kant definiu que o ser humano percebe os objetos inicialmente pelos sentidos, ordenando essas percepções mentalmente, para depois pensá-las e delas extrair os conceitos. Mas, para que esta ordenação seja possível, é preciso situar esses objetos no tempo e no espaço, os quais Kant considerou como inerentes ao indivíduo, e os denominou de formas a priori da sensibilidade. Tempo e espaço não existem enquanto realidade externa. O tempo, na verdade, é apenas um modo pelo qual a sensibilidade organiza os eventos para que eles possam ser pensados, pois, se esta não o fizesse, os acontecimentos se encontrariam numa ordem inteiramente difusa, e não poderiam ser compreendidos. O tempo é, portanto, uma condição para a percepção dos eventos, sem a qual estes se perderiam por não poderem ser organizados em uma sucessão.

Com relação ao espaço, Kant irá argumentar que, se forem retiradas de um objeto todas as suas qualidades, a única coisa que restará é o espaço. Logo, o espaço não pode ser entendido como uma propriedade do objeto, e sim como um artifício humano para que este seja percebido. O espaço é, portanto, uma forma de apreensão das coisas, e um requisito para a percepção destas.

O mundo do homem é o mundo dos fenômenos, das coisas sensíveis. Kant considera que ao ser humano é dado conhecer tão somente a forma de manifestação desses fenômenos e que as limitações impostas pelos sentidos não permitem que se possa chegar ao ser em sua essência, à coisa em si. Porém, tal pressuposto da teoria kantiana não poderá ser encontrando em Karel Kosik, pois, segundo este, a coisa-em-si não se encontra desprendida do fenômeno e tampouco é inacessível ao homem. Ela pode ser alcançada, contanto que para isso se faça um esforço e desvio do pensamento, o que pode ocorrer apenas por meio do conhecimento filosófico e científico.

Mas, mesmo esta aparente cisão entre a filosofia de Kosik e a kantiana pode desaparecer, caso levemos em conta o que afirma o filósofo alemão no capítulo primeiro da estética transcendental, no que diz respeito à distinção entre entendimento e sensibilidade.

A capacidade de receber representações (receptividade) graças à maneira como somos afectados pelos objectos, denomina-se sensibilidade. Por intermédio, pois, da 
sensibilidade são-nos dados objectos e só ela nos fornece intuições; mas é o entendimento que pensa esses objectos e é dele que provêm os conceitos (KANT, 1985, p. 61)

Sendo assim, a sensibilidade irá corresponder ao universo das representações, campo em que se manifesta a pseudoconcreticidade. $\mathrm{O}$ mundo pseudoconcreto é, portanto, o mundo que se encontra antes do detour, do desvio que leva ao conhecimento da realidade, ou seja, um estado anterior ao do entendimento, de onde se originam os conceitos, a realidade pensada. $\mathrm{O}$ conceito, então, termina em relacionar-se com a essência, que, por meio de sua ligação com a sensibilidade, torna possível o acesso ao real.

Temos, aqui, uma estreita correspondência entre o concreto/ pseudoconcreto kosikiano e a sensibilidade/entendimento de Kant. Ambos representam duas etapas imprescindíveis do processo epistêmico dentro da construção da teoria do conhecimento dos dois filósofos, sem as quais a cognoscibilidade não pode se dar tanto no pensamento de um quanto de outro. Para Kant, o conhecimento é a conformidade entre o conceito e o objeto, a qual é dada a partir da relação entre a sensibilidade e o entendimento, enquanto que, em Kosik, este se forma por meio de um exercício dialético envolvendo a representação e a essência. A ideia contida em Kosik é que a coisa em si pode ser alcançada enquanto que em Kant ela é incognoscível e não representa uma oposição das duas teorias. Elas continuam se assemelhando quanto ao processo pelo qual o conhecimento é obtido pelo homem. Em seus edifícios intelectuais, as duas terão a mesma constituição, sendo a possibilidade ou não de uma coisa em si pouco determinante para o mapeamento da epistemologia dos dois autores.

Nesse ponto, o pensamento de Kosik é um refinamento, uma releitura bastante elaborada da filosofia kantiana. Porém, por força de sua importância dada à dialética, seria bastante plausível inquirir se a fundamentação teórica da dialética do concreto não se encontra exclusivamente em Marx, e o que de kantiano há em Kosik é justamente aquilo que Marx absorveu do pensamento do filósofo de Konigsberg.

$\mathrm{Na}$ verdade, tal como em Kosik, Marx irá definir a matéria como algo independente da consciência humana, e que todo conhecimento deve provir de uma observação aguda da realidade e que vise ao descobrimento de sua 
essência. Só que, em nenhum momento, Marx irá discutir profundamente os processos do conhecer humano, os elementos que "permitem, no homem, a transformação do mundo exterior em conhecimento" (ANDERY, SÉRIO, 1999, p. 402). Ideias como percepção, razão, coisa em si, númeno e fenômeno, não são objetos de um exame mais apurado por parte da filosofia marxiana. Também, em Marx, não haverá uma discussão em torno da diferença entre essência e representação. Os seres são tais quais se apresentam na realidade, cabendo ao homem apenas um estudo minucioso sobre eles para atingir a sua real natureza. As ideias, longe de construírem um mundo ideal e perfeito, são a transposição da matéria para a mente humana. Para Marx, mais importante do que discutir as possibilidades do conhecimento, era o estudo das relações entre homem, natureza e sociedade, aí residindo verdadeiramente o problema da produção do conhecimento.

Para ele, o homem é parte da natureza, mas se distingue dela por ser o único capaz de transformá-la e, com isso, transformar também a si mesmo. E essas transformações são motivadas em razão das necessidades humanas, necessidades estas que surgem não pela vontade de um só indivíduo, mas de uma coletividade. Assim, o que determina o curso das transformações no homem é o seu ser social, construído mediante as diversas condições sociais e históricas que a ele se apresentam.

Portanto, em Marx, pensar sobre a produção do conhecimento humano é refletir sobre as condições dadas ao indivíduo e sobre as demandas que o fizeram produzir um determinado saber, sem fazer distinção entre aquilo que é material ou ideal, tomando a realidade como algo dado na matéria e que cabe ao homem tão somente investigá-la corretamente.

Desse modo, o pensamento de Kosik encontrará em Kant um receptáculo mais adequado para suas discussões sobre o fenômeno e a essência, a coisa em si e sua representação, a aparência e a realidade.

\section{O ponto de separação}

E em que momento ocorre, portanto, a cisão entre esse dois filósofos? Em que elemento eles encontram a fronteira que permite distingui-los e situálos dentro de duas diferentes tradições de pensamento? 
$\mathrm{Na}$ práxis, na relação com o mundo. Se, para Kant, interessava muito mais saber quais são os limites da razão cognoscente, Kosik afirmará que todo pensamento deve manifestar-se primordialmente enquanto ação, como forma de interferir objetivamente na realidade.

\begin{abstract}
A atitude primordial e imediata do homem, em face da sua realidade, não é a de um abstrato sujeito cognoscente, de uma mente pensante que examina a realidade especulativamente, porém, a de um ser que age objetiva e praticamente (KOSIK, 2002, p. 13).
\end{abstract}

O homem não pode ser entendido como um ser meramente contemplativo, que busca somente erguer teoricamente o mundo. Ele age sobre a realidade, atua sobre ela e dessa experiência ele extrai uma intuição prática da realidade, a partir da qual ele cria suas próprias representações, as quais, ao ganharem autonomia, aparecem como um pensamento comum que finda pelo fato de reger a práxis, dando então origem ao mundo da pseudoconcreticidade.

Tais considerações irão alinhar-se perfeitamente com o pensamento de Marx, que considera que o ser humano se apresenta essencialmente como ser prático e que se afirma de acordo com suas ações.

A questão de atribuir ao pensamento humano verdade objetiva não é uma questão teórica, mas sim uma questão prática. É na práxis que o homem precisa provar a verdade, isto é, a realidade e a força, a terrenalidade do seu pensamento. (MARX, ENGELS, 2002, p. 100).

Para Marx, o pensamento se concretiza como plena atividade humana, que visa à resolução de problemas práticos, concepção esta muito distante das abstratas considerações do idealismo hegeliano, que é devedor de Kant e do qual Marx foi crítico contumaz. O homem se realiza na medida em que produz ativamente, em que transforma a realidade que o cerca e a adapta de acordo com suas intenções, sendo que o exercício intelectual não foge a esta regra. De acordo com Marx, pensar deve ser, sobretudo, um pressuposto para a ação, a tal ponto que o próprio pensamento se converte em atividade prática e interventora da realidade. 
Em Karel Kosik, as concepções marxianas irão ganhar vigor principalmente em sua proposta de dialética. Se a pseudoconcreticidade diz respeito ao modo de representações reificadas que chegam ao indivíduo por meio de sua experiência cotidiana, é necessário que se criem métodos pelos quais o rompimento com esse estado de coisas seja possível, e a essência possa ser revelada. Segundo Kosik, esse método seria a dialética, que coloca em oposição os elementos constantes da pseudoconcreticicade, destruindo a aparente independência das formas pseudoconcretas e pondo em questão as possibilidades de desvelamento da essência. A dialética, considera Kosik, é o único meio capaz de dar conta de reagrupar representação e essência, de restabelecer uma relação entre estas e restaurar a unicidade que torna a compreensão do real alcançável, negando ao mesmo tempo "a sistematização doutrinária" (KOSIK, 2002, p. 20) e a "romantização das representações comuns" (KOSIK, 2002, p. 20) que vigoram no mundo das aparências reificadas. Assim, o pensamento dialético busca escapar das concepções idealísticas do real, e tenta apreendê-lo em sua concreticidade, manifestando mais uma vez o caráter prático do pensar humano, que tem a missão fundamental de saltar do mundo das aparências para uma visão concreta da realidade.

Porém, a dialética não irá negar nem tampouco rechaçar a presença das representações. Também não irá tomá-las como idênticas à essência. Seu exercício consiste em romper com a autonomia das formas representativas para, com isso, atingir a coisa em si e interpretar a realidade. Logo, o estudo dialético precisa antes de tudo separar corretamente o que é essencial do que é secundário, sem com isso desprezá-lo enquanto integrante da realidade. O processo dialético é, portanto, um intenso jogo de diluição das formas concretas e ideais, que busca por esse processo encontrar as diversas conexões entre os fenômenos, os quais perdem sua independência e são assumidos como elementos constituintes e não essenciais da práxis humana.

E aqui ganha grande importância o papel da crítica. O homem é produto e produtor da verdade, que se manifesta de forma inconstante e está em contínuo processo de produção. Mas, a verdade somente se revelará ao homem caso pensemos criticamente o real. Desse modo, o pensamento dialético-crítico é o único que pode desfazer as fetichizações do mundo idealizado e reificado e interpretar a realidade de modo concreto, o que se dará ao mesmo tempo em que se realiza uma práxis revolucionária, pois o pensamento não se encontra 
dissociado da ação. Porém, nenhuma verdade é permanente. Ela acompanha as diversas transformações humanas, ou seja, a verdade é devir. Construir a história do homem é dar movimento ao processo de construção da verdade, a qual será sempre provisória, e será revelada somente por meio da ação dialético-crítica que poderá desmistificar o edifício da pseudoconcreticidade.

Dessa forma, considera Kosik, é contrário ao processo epistemológico uma absolutização do sujeito, como queriam os idealistas, tampouco se valorizar exclusivamente o objeto, extirpando completamente o indivíduo. A dialética é justamente o meio a partir do qual se unem sujeito e objeto, e a realidade advinda dessa elisão torna-se presente. Pensar dialeticamente é compreender o mundo em sua totalidade.

Nesse momento, tem-se novamente clara a ligação estabelecida entre Kosik e Kant, bem como os aspectos que permitem sua separação dele, e também a consequente união com a corrente marxiana. Por mais que Kosik concorde com Kant sobre as relações que ligam o sujeito ao objeto, ou sobre seus postulados acerca de fenômeno e essência, o fim último e principal da atividade intelectual do homem é a compreensão e transformação da realidade por meio de uma práxis revolucionária, pois é no mundo que a verdade se mostra e se desenvolve enquanto história. Assim, na visão kosikiana, a filosofia de Kant se mostra insuficiente para ampará-lo no projeto filosófico que deseja empreender, o que leva inevitavelmente Kosik ao encontro de Marx.

Contudo, é preciso que se ressalte a contribuição da estética transcendental no pensamento de Kosik, e seu esforço, que revelou-se prolífico, de dialogar com a tradição kantiana. E são esses diálogos, aliados à releitura das ideias de Marx, os elementos que garantem a consistência e a originalidade de seu pensamento.

\section{Considerações finais}

A tarefa fundamental da Filosofia é chegar à essência e, com isso, romper com as formas reificadas e a autonomia da representação que compõem o mundo da pseudoconcreticidade. Esta é a proposta inicial da Dialética do Concreto e o elemento orientador de toda a reflexão Kosikiana.

Porém, para que se atinja tal objetivo, é preciso que antes se crie uma epistemologia capaz de revelar de que forma esse mundo pseudoconcreto 
pode ser apreendido, o que só é possível mediante a discussão de conceitos como fenômeno e coisa em si, ponto em que é fundamental a contribuição do pensamento Kantiano.

Em contrapartida, somente a análise das condições de produção do conhecimento não é suficiente para destituir as formas de manifestação da pseudoconcreticidade. Para tanto, é preciso que o pensamento alcance a percepção concreta do real, dada a partir da relação entre representação e essência. O pensamento, para compreender o mundo em sua concretude, precisa atuar sobre a realidade, convertendo-se em ação. Eis aí um pressuposto da filosofia de Marx.

Desse modo, a Dialética do Concreto de Karel Kosik se apresenta como um esforço de agregar as duas teorias, num movimento que possui traços de dialético. A estética transcendental kantiana corresponderia à tese. A filosofia de Marx, à antítese, enquanto que a obra de Kosik seria a síntese, o novo, o movimento revolucionário do pensamento que busca acompanhar o devir do mundo e compreendê-lo em sua totalidade.

\section{Referências}

ANDERY, Maria Amália Pie Abib. SÉRIO, Tereza Maria de Azevedo Pires. A prática, a História e a construção do conhecimento: Karl Marx. In: Para compreender a ciência - Uma perspectiva histórica. São Paulo/Rio de Janeiro: Educ, Espaço e Tempo, 1999.

KANT, Immanuel. Crítica da razãa pura. Lisboa: Calouste Gulbenkian, 1985.

KOSIK, Karel. Dialética do Concreto. 7. ed. Rio de Janeiro: Paz e Terra, 2002.

MARX, Karl. ENGELS, Friedrich. A ideologia alemã. São Paulo: Martins Fontes, 2002.

MOROZ, Melania. RUBANO, Denize Rosana. A dúvida como recurso e a geometria como modelo: René Descartes. In: Para compreender a ciência - Uma perspectiva histórica. São Paulo/Rio de Janeiro: Educ, Espaço e Tempo, 1999 